\title{
Cartografia da luta e resistência de uma comunidade de pesca artesanal
}

\author{
Cartography of the struggle and resistance of an artisanal fishing \\ community
}

Antonio Vladimir Félix-Silva', Maylla Maria Souza de Oliveira', Laís Leal da Silva Bezerra'

DOI: 10.1590/0103-11042020E221

RESUMO Os povos do mar estão ameaçados pela produção de subjetividade colonial capitalística que, por meio do dispositivo estado de exceção, tem o poder de fazer morrer os modos de viver em comunidade nos territórios das águas. Nesta cartografia, objetivou-se analisar processos de subjetivação, luta e resistência de pescadoras e pescadores artesanais de uma comunidade ante os empreendimentos eólicos na Planície Litorânea do Piauí, situada no Nordeste do Brasil. Trata-se de um modo de fazer pesquisa-intervenção, na qual se utilizou a participação observante para a produção de dados, compondo reuniões, encontros e audiências públicas com os participantes da pesquisa, além do uso de diários cartográficos para registros de relatos e escrita de si. A discussão e a análise dos resultados mostram a soberania do capital impactando a determinação social da saúde ao afetar as ecologias ambiental, subjetiva e social; luta e resistência como dimensões política da vida e de saúde como potência de vida; coexistência de políticas de morte e linhas de força da vida em comunidade; processos de subjetivação que ora expressam assujeitamentos, ora expressam singularizações ao agenciar coletivamente o desejo de resistência às políticas impostas pelo dispositivo estado de exceção.

PALAVRAS-CHAVE Pesqueiros. Racismo. Política. Saúde ambiental.

ABSTRACT The peoples of the sea are threatened by the production of capitalistic colonial subjectivity
which, through the state of exception device, has the power to make the ways of living in community in the
water territories die. In this cartography, the objective was to analyze processes of subjectivation, struggle
and resistance of artisanal fisherwomen and fishermen in a community in the face of wind farms in the
Coastal Plain of Piaui, located in the Northeast of Brazil. It is a way of doing research-intervention, in which
observant participation was used for data production, arranging reunions, meetings, and public hearings
with the research participants, in addition to the use of cartographic journals for the recording of reports
and writing of themselves. The discussion and analysis of the results show the sovereignty of capital, impact-
ing the social determination of health by affecting environmental, subjective and social ecologies; struggle
and resistance as political dimensions of life and health as a power of life; coexistence of death policies and
community life force lines; subjectivation processes that sometimes express subjections, sometimes express
singularities when collectively managing the desire to resist policies imposed by the state of exception device.

KEYWORDS Fisheries. Racism. Politics. Environmental health. 


\section{Introdução: cartografia socioambiental}

No Brasil, a guerra econômica permanente aos territórios tradicionalmente ocupados é expressão da genealogia de uma produção de subjetividade colonial-capitalística'. Guerra à Amazônia, ao meio ambiente e seus ecossistemas, guerra do capital contra a existência das comunidades tradicionais e das minorias que não comungam com a soberania do capital e com a expansão do capitalismo contemporâneo.

Essa [...] guerra é econômica, política, jurídica, militar, midiática [...] embora queiram nos fazer acreditar que tudo está sob a mais estrita e pacífica normalidade institucional, social, jurídica, econômica2(5).

Como sabemos, a história da exploração econômica colonial iniciou-se, no século XVI, com a comercialização desenfreada que levou à extinção de aproximadamente 70 milhões de espécimes da "ibirapitanga, nome dado pelos índios Tupi da costa"3(31) à árvore que recebeu o nome de pau-brasil. Sem dúvida, essa história foi forjada em racismo ambiental e genocídio, subordinação e expulsão de nativos, tráfico e escravização do povo negro, interdição do corpo da mulher, massacres e sucessivas tentativas de eliminar a cosmologia de religiões de matrizes indígena e africana ${ }^{3-6}$. Foi assim que o racismo passou a se configurar como um problema histórico, conformando até hoje a determinação social da saúde.

A partir da concepção de Robert Bullard, apresentada por Victor de Jesus, entendemos por racismo ambiental, uma dimensão do racismo institucional que pode ser definido como:

[...] qualquer política, prática ou diretiva conduzida por instituições governamentais, jurídicas, econômicas, políticas e militares que afete ou prejudique racialmente, de formas diferentes, voluntária ou involuntariamente, as condições ambientais de moradia, trabalho ou lazer de pessoas, grupos ou comunidades ${ }^{7(6)}$.
O trauma da fundação do Brasil e o racismo ambiental com o qual operam as instituições de violência nas comunidades tradicionais ainda estão longe de ser superados, haja vista as políticas de morte mediadas pelo dispositivo estado de exceção que, desde a colonização, opera na perspectiva de:

[...] uma exclusão inclusiva da vida humana [politicamente qualificada] na forma de vida nua [vida natural] [...], ou seja, de uma vida que foi cindida e separada de sua forma8(295).

Dessa forma, tratando de subtraí-la de sua dimensão política (bios) e de reduzi-la à dimensão, puramente, animal (zoé). Tal despolitização das formas de vida dificulta a desativação desse dispositivo que "designa acima de tudo uma vida que se pode matar sem cometer homicídio"8(295), ainda que não possamos deixar de reconhecer que um dos efeitos dessa guerra permanente contra pobres, indígenas, negros, mulheres e transexuais ${ }^{2}$, no Brasil, seja a morte desses sujeitos e a morte de lideranças do campo, das florestas e das águas.

Na contemporaneidade, os povos do mar, das águas e das florestas que mantêm traços de alteridade-solidariedade, reciprocidade e pertencimento ao seu território de existência ${ }^{9}$ convivem, forçadamente, com a invasão de seus territórios pelos empreendimentos relacionados com o agronegócio, com a especulação imobiliária e seus condomínios fechados; com a instalação de hidrelétricas, mineradoras e eólicas. Como se não bastasse conviver com tudo isso, as pescadoras e os pescadores artesanais enfrentam a negação de direitos ainda não conquistados, como a demarcação do território das águas, além da perda de direitos constitucionais e da não efetivação de políticas públicas instituídas a partir da Constituição Federal de 1988 e da regulamentação das políticas de promoção da equidade em saúde, entre 2003 e 2015; hoje, ameaçadas.

Em 2018, o Brasil atingiu o $8^{\circ}$ lugar em relação à geração de energia eólica "instalada (U.S. Department of Energy, 2018)"10(25); isso se 
deve a políticas de investimento, principalmente nos Estados da região Nordeste, nos quais a extensão territorial de parques atinge até 5 $\mathrm{km}$ da costa. No Estado do Piauí, destacam-se os empreendimentos que vêm acontecendo, especialmente no entorno dos municípios de Paulistana e Parnaíba, "regiões favoráveis para o aproveitamento da energia eólica [...], [onde existem] os melhores valores de velocidade média horária e mensal do vento"11(743). No contexto da pesquisa que gerou este estudo, os processos de subjetivação relacionados a essa problemática expressam a correlação de forças da vida e as políticas de morte e precarização da vida em um campo de disputas entre as instituições de agenciamento dos empreendimentos eólicos e as comunidades da Área de Proteção Ambiental (APA) Delta do Parnaíba, cujo plano de manejo das atividades econômicas só foi discutido, entre 2018 e 2019, 22 anos depois de sua criação.

A APA foi criada pelo Decreto $n^{0} 1.922 / 96$, e abrange três estados: Piauí, onde atinge os municípios de Cajueiro da Praia, Luiz Correia, Parnaíba e Ilha Grande; Maranhão, demarcando os municípios de Araioses, Água Doce, Tutóia e Paulino Neves; e Ceará, onde perpassa os municípios de Barroquinha e Chaval12. $\mathrm{Na}$ APA, há séculos, o extrativismo é praticado, incluindo a atividade da pesca artesanal em suas diversas modalidades: pesca em água salgada, em água doce, no mangue. A região é abundante em variedade de frutas e de crustáceos, entre eles: o marisco, o camarão, a ostra, a lagosta e o caranguejo. As características dos recursos naturais da região da Planície Litorânea fazem com que pescadoras e pescadores artesanais desenvolvam mais de um tipo de extrativismo, o que a Classificação Brasileira de Ocupações (CBO) denomina de pescador polivalente ${ }^{13}$.

\section{$O$ contexto da pesquisa}

Neste artigo, apresentamos uma cartografia da luta e resistência de uma comunidade de pesca artesanal da Planície Litorânea do Piauí diante dos empreendimentos de geração de energia da Usina Eólica Ômega (UEO), denominados Delta 1 (D1), instalado em 2014, e Delta 2 (D2), instalado em 2016, totalizando 62 aerogeradores no entorno da praia e do território das águas da Pedra do Sal/Parnaíba (PI). O processo de licenciamento ambiental do projeto Delta 10 (D10) (2019/2020), que se encontra em curso, teve licença prévia emitida pela Secretaria Estadual de Meio Ambiente e Recursos Hídricos do Piauí - Semar (PI), em dezembro de 2019. Isso implica a ampliação do parque eólico, com instalação de mais 52 aerogeradores em áreas do território que pertencem à Parnaíba (PI) e à Ilha Grande (PI), cujas certidões já foram emitidas pelos gestores desses municípios. Em desacordo com o Plano Diretor de cada município, isso afetará mais ainda a segurança alimentar da comunidade e o acesso ao trabalho e à renda, haja vista que atingirá áreas prioritariamente destinadas ao turismo comunitário, cujo projeto está em andamento, à criação de animais e de gado de pequeno porte e ao extrativismo de frutas e de outros produtos, conforme análise do relatório do Estudo de Impactos Ambientais (EIA), produzido pela consultora Mineral Engenharia e Meio Ambiente a pedido da UEO"1.

Ilha Grande tem uma população de 8.734 habitantes, sendo 4.556 homens e $4.178 \mathrm{mu}$ lheres, a maioria parda e preta ${ }^{\mathbf{1 4}}$. A cidade está cercada de rios e dunas, onde se localiza a sede da Associação de Marisqueiros de Ilha Grande, sendo mais conhecida como Casa das Marisqueiras. Pedra do Sal, praia situada no litoral do Estado do Piauí, zona rural da cidade de Parnaíba, é banhada por uma costa de mar que está dividida em lado bravo (um espaço com mais ondas agitadas) e lado manso ou enseada (mar calmo, com menos ondas). A praia, considerada um ponto turístico, fica a $15 \mathrm{~km}$ do centro da cidade; e seu acesso se dá pela rodovia PI-116, cujo asfalto está sem sinalização e com trechos totalmente destruídos. A população é de aproximadamente 1.500 habitantes segundo o mapa da Unidade Básica 
de Saúde (UBS) da Pedra do Sal15; a maioria não se diferencia da população de Parnaíba, que corresponde a $65,11 \%$ entre pardos e pretos ${ }^{14}$. $\mathrm{Na}$ Pedra do Sal, mais de 50\% fazem parte, diretamente ou por extensão, da comunidade de pesca artesanal; não são todos contra os empreendimentos econômicos de grande porte, mas apenas uma minoria se manifesta a favor por se beneficiar de alguma forma ou ter esperança de que poderá se beneficiar com a ampliação do parque eólico.

Nas comunidades afetadas pelos empreendimentos eólicos nos dois municípios, vivem pescadoras e pescadores artesanais, marisqueiras, catadores de caranguejos e manjubeiros, bordadeiras da Pedra do Sal, artesãs dos Trançados da Ilha, estilistas que produzem figurinos e artistas que produzem artes plásticas, redes e trançados feitos com palha de carnaúba e artesanatos de outros artefatos encontrados e extraídos em torno do território das águas. Dependendo da época, há mulheres que acordam cedo para trabalhar com o extrativismo de caju, murici, murici-pitanga, puçá e guajiru ou outras frutas de época; há criadores de animais, como bois, cabras, galinhas, que o fazem para subsistência e por alguma venda, além de pequenos comerciantes locais que têm bares, pequenas pousadas e pequenos restaurantes à beira mar. Destacamos quadrilhas, grupos de dança, Boi Estrela do Mar, Boi da Ilha; o mestre de coco, cantador, poeta e pescador, seu Garajau; o Festival do Marisco; a Festa de Bom Jesus dos Navegantes, a Festa de São Pedro, a Regata e as festas e oferendas a Iemanjá que são realizadas anualmente, dia dois de fevereiro e dia 15 de agosto.

A história dessas comunidades, tradicionalmente ocupadas por pescadoras e pescadores artesanais, faz parte da história dos povos do mar e atravessa diversas gerações. Seu Pescada (70 anos) faz as contas a partir de seu bisavô e de seus antepassados, afirmando que sua família está nesse território há mais de 250 anos. A principal fonte de renda e sustentabilidade é a produção econômica de base familiar, por meio do extrativismo da pesca artesanal e de outros produtos. De acordo com a Política Nacional de Saúde Integral das Populações do Campo e da Floresta, pescadoras e pescadores artesanais são extrativistas, ou seja,

[...] pessoas e comunidades, com suas especificidades culturais, cuja produção de riquezas para o seu desenvolvimento tem por base a coleta de produtos de fontes naturais, como as matas, capoeiras, rios, igarapés, lagos, várzeas, manguezais, igapós, praias oceânicas, e alto-mar, dentre outros'6(21).

Esse modo de vida se vê ameaçado pelos empreendimentos eólicos em vários aspectos, tanto no âmbito da territorialização e limitação do campo de realização da pesca artesanal e de outras atividades extrativistas, infringindo o direito de ir e vir da comunidade ao limitar as formas de acesso, quanto pelo corte de cajueiros, aterramento de lagoas, contaminação do lençol freático; alteração do fluxo de peixes entre águas doces e salgadas, mudança no ciclo de aves migratórias e morte de outras. O desequilíbrio provocado pela geração da chamada 'energia limpa' afeta as ecologias: ambiental, subjetiva e social17, isto é, afeta a saúde e sua determinação social, como mostraremos a partir das narrativas da comunidade, com os atravessamentos e as transversalidades que marcam a análise dos processos de subjetivação cartografados.

Diante dessa situação-problema, como se constituem os processos de sujeição, a luta e a resistência ante os empreendimentos eólicos em territórios existenciais tradicionalmente ocupados por pescadoras e pescadores artesanais? Para pensar tal problematização, apresentamos um recorte de uma pesquisa-intervenção (CAAE 03051018.8.0000.5214) sobre processos de subjetivação, movimentos sociais e determinação social da saúde de pescadoras e pescadores artesanais da Planície Litorânea que vivem no território das águas que compõe a APA Delta do Parnaíba.

No presente artigo, apresentamos somente a produção de conhecimentos gerados pelos 
objetivos: a) Cartografar processos de luta e resistência de pescadores e pescadoras artesanais diante dos empreendimentos econômicos de uma eólica; b) Mapear impactos gerados pela implantação, instalação e operação do D1 e do D2 nos modos de viver de pescadoras e pescadores artesanais e no território tradicionalmente ocupado pela comunidade pesqueira; e c) Caracterizar a luta das comunidades de Pedra do Sal e Ilha Grande para barrar o empreendimento $\mathrm{D} 10$, a partir da problematização dos modos de sujeição e do reconhecimento dos modos de vida que resistem às políticas de morte ao território das águas.

\section{Cartografia como modo de fazer pesquisa-intervenção}

Nesse contexto de disputas, as intervenções são produzidas pela comunidade, de modo que o pesquisador e as pesquisadoras compõem as cartografias da luta traçadas pelo movimento de resistência. Esta cartografia se configura como modo de fazer pesquisa-intervenção e como método de pesquisa qualitativa em psicologia, possibilitando que a estratégia de produção de dados, denominada observação participante, descoloque-se para participação observante ${ }^{18}$. Para a produção das informações, utilizamos a cartografia de narrativas, oralidade e escrita de si, na perspectiva foucaultiana do dizer verdadeiro ${ }^{19,20}$ com registros em diários cartográficos, a partir da composição de diversas paisagens psicossociais, entre 2018 e 2019. Portanto, tivemos como estratégia metodológica a participação observante nos seguintes momentos: a) Uma Tenda de Artes e Educação em Saúde e sete Conversas de Pescador para ouvir narrativas e contos à beira da praia, na Pesqueira, casa localizada na Pedra do Sal, que serve de suporte para guardar artefatos da pesca, local de passagem para quem vai e volta do mar; b) Semana do Pescador, da Pesca e da Aquicultura, em Luís Correia (PI); c) I Seminário de Povos Tradicionais da Região Norte do Piauí na
Universidade Federal do Piauí (UFPI); e d) Quatro reuniões organizadas pelo ICMbio para elaboração do plano de manejo da APA Delta; e) Duas reuniões coletivas, organizadas pelo empreendimento eólico; f) três reuniões com a comunidade, realizadas antes das audiências, em Ilha Grande e na Pedra do Sal; e g) Duas audiências públicas coordenadas pela Semar, realizadas dia 14 de agosto de 2019, em Ilha Grande, e dia 15 de agosto de 2019, na Pedra do Sal - além da participação em reuniões, encontros, fóruns e protestos, quando do enfrentamento aos empreendimentos relacionados com a construção de resorts, evento de kitesurf e audiências públicas relativas à apresentação dos EIA e à licença para instalação do D1 e D2.

\section{Discussão, resultados e análise cartográfica dos processos de subjetivação}

Em uma roda de conversa para contação de história e narrativas da comunidade, realizadas por professoras(es) da UFPI, Seu Zé Boreta (atualmente, com 60 anos) narra:

[...] Estamos impedidos de realizar nosso extrativismo vegetal pela poda de nossa liberdade de ir e vir em nossas terras. A gente, que vive há muito tempo aqui, ainda não tem a posse de nossa terra. Mas, uns estrangeiros que chegam já se dizem donos. Isso é um abandono do governo com a população. É engraçado, mas é real, pois nós é que escolhemos as armas para nos matar ao escolher nossos representantes políticos que nos deixam no abandono. E agora, o que será de nossa Pedra do Sal: Só o futuro nos dirá. O que pudermos fazer para impedir essa destruição em massa, faremos, lutaremos 21(33).

Os decretos, as leis e as licenças ambientais compõem o ordenamento político-jurídico para exploração desse grande empreendimento econômico, constituem as políticas de morte ou as armas denunciadas por Seu Zé Boreta. Há um paradoxo 
relacionado com o acesso ao território das águas, haja vista que está em curso uma proposta de urbanização da Pedra do Sal; ao mesmo tempo, está em andamento um processo de regularização fundiária, cuja solicitação foi iniciada em 2014 e retomada em 2016 por outra gestão da Associação Comunitária. A falta de Cadastro Ambiental Rural (CAR) comunitário gera conflitos entre 'donos' das terras aforadas e a comunidade. Não obstante, em algumas comunidades dos municípios do Maranhão, a UEO e os governos estão incentivando o CAR, para que as associações comunitárias possam arrendar a área para instalação e operacionalização de eólicas. Tal agenciamento expõe a comunidade a processos de subjetivação e de sujeição que definem 'justamente o biopoder'22, o poder sobre a vida.

Em sua tese, Eugênia Figueiredo ${ }^{23}$ mostra como, em 2005, a comunidade - com o apoio das instituições da justiça e do direito ambiental, Ministério Público, ICMbio, Ibama e de professoras(es) da UFPI - se mobilizou: entrou com pedido de liminar e conseguiu barrar a licença ambiental para a construção de um complexo empreendimento turístico na Pedra do Sal, que pretendia, exatamente, remanejar a comunidade para outra área e construir um condomínio fechado com heliporto, quadras esportivas e campo de golfe. Em 2015, os empreendedores voltaram; dessa vez, a construção seria em uma área da praia que pertence à União e afetaria a pesca, o mangue, as dunas e as lagoas. Figueiredo conta que a força do capital se impôs de tal forma que a voz da comunidade não foi escutada, mesmo tendo se manifestado em "audiências públicas, em atos de protesto e em reuniões com empresários e órgão de fiscalização (ICMbio, SEMAR)"23(107).

Na Tenda de Artes e Educação em Saúde (TeArES) que organizamos, Seu Buchudo (55 anos), ao se referir à comunidade Pedra do Sal, afirma:

aqui era uma terra comum, com direito e liberdade de ir e vir, antes da chagada da eólica [...] Aqui, agora, é viver ou morrer! A saúde é precária!
Na cidade de Paranaíba-PI, apenas 23,5\% de domicílios têm esgotamento sanitário adequado, e na cidade de Ilha Grande-PI, são apenas $4,4 \%$ de domicílios com esgotamento sanitário adequado $^{\mathbf{1 4}}$. Nas comunidades em que vivem as pescadoras e os pescadores artesanais, não há coleta de lixo em todos os locais e, além da falta de saneamento básico, muitas vezes, não há água potável. Há áreas descobertas no território por falta de Agentes Comunitários de Saúde (ACS); e, na Pedra do Sal, já não havia visitas domiciliares pelas equipes da Estratégia Saúde da Família (ESF) antes da extinção do Núcleo de Apoio à Saúde da Família (Nasf).

À diferença dos monarcas absolutistas que exerciam o poder de fazer morrer e deixar viver até os séculos XVI, XVII e XVIII ${ }^{24}$, como modo de se sustentar e de manter os súditos na ignorância e total obediência, na sociedade contemporânea, a necropolítica é uma das formas de defender o processo de modernização viabilizado pela colonização e globalização e sustentado pela ampliação da precarização da vida. Nos contextos de globalização da economia, financeirização dos empreendimentos e concentração do lucro, os chamados Estados-nações se ocupam cada vez menos com fazer viver e com a vida de algumas populações de classes e grupos sociais considerados vulneráveis, controlando taxas de natalidade e longevidade, e se ocupam cada vez mais em "como salvar a economia, a vida do capital"25(9).

Da escravidão à globalização da economia, o capital vem se impondo ao que resta de Estadonação e agenciando políticas de morte que marcam o capitalismo contemporâneo em diversos contextos. Nesse sentido, a escravidão é considera por Mbembe como "uma das primeiras manifestações da experimentação biopolítica"26(27), sendo o estado de exceção, de acordo com Agamben ${ }^{\mathbf{8 2 2}, 27}$, o dispositivo de agenciamento da dimensão política da vida (bios) e da vida nua (zoé); tal dispositivo serve para regular, por meio do ordenamento jurídico-político, a soberania do capital. No contexto da pesquisa, isso fica evidente com o 
incentivo às empresas, à isenção fiscal e às licenças prévias para empreendimentos econômicos de grande porte, além de decretos e projetos de lei que garantem que a APA possa ser explorada para expansão do turismo comercial.

"[...] O território é vida. Água é vida [...]. O capital é a morte. Morte ao território das águas. Morte à vida de humanos e não humanos [...]”. Mesmo com algumas variações, esses são enunciados da tese de D. Celeste (65 anos), pescadora artesanal e uma das coordenadoras do Movimento de Pescadores e Pescadoras (MPP). É assim que ela inicia e conclui sua participação nas rodas de conversa. Para além do lugar de fala e representatividade ${ }^{28}$ referente ao MPP que cobre 18 estados do Brasil, seu relato e a escrita de $\mathbf{s i}^{19,20}$ são expressões de processos de subjetivação que configuram potência de vida, expressão de saúde comunitária como capacidade de atualizar as forças da vida por meio da luta política e da resistência ativa.

Encontramos convergência entre o que denunciam os enunciados de D. Celeste e a concepção de produção de subjetividade colonial-capitalística ${ }^{1}$, nos contextos da sociedade contemporânea, nos quais nos tocam morrer, mas nos quais teimamos em viver, coexistir e resistir como minorias: periféricas, candomblecistas, umbandistas, ayahuasqueiros, indígenas, negras(os), mulheres, lésbicas, gays, travestis, transexuais, intersexos etc. A tese de D. Celeste, defendida coletivamente pelos movimentos sociais, povos e comunidades tradicionais, traduz essa concepção de subjetividade, essencialmente fabricada pelas instituições da sociedade de controle, ora sustentada pelo desejo servil à produção de um inconsciente colonial-capitalístico ${ }^{\mathbf{1 , 2 9}}$, ora problematizada pelo agenciamento coletivo do desejo de comunismo, desejo de mundo que se torna devir comum minoritário ${ }^{30,31}$. $\mathrm{Na}$ comunidade tradicional de pescadoras e pescadores artesanais, o que sustenta a luta política pela vida é a resistência contra a norma necropolítica do estado de exceção que caracteriza o capitalismo contemporâneo "que pretende ditar todas as formas de filiação"32(4), puxando para as malhas dessa produção de subjetividade colonial-capitalística todas(os) nós.

A tessitura das bordadeiras da Pedra do Sal e os Trançados da Ilha expressam elementos do território das águas, de modo que as linhas da pesca, da arte de bordar e dos artefatos da pesca vão se misturando com as linhas e forças da vida. Assim, reconhecemos processos de semiotização na arte, na luta e na resistência da comunidade que coexistem com processos de subjetivação e dessubjetivação. Enquanto pescam ou catam frutas, conversam sobre a vida; algumas famílias 'cantam': "é da pesca que vivemos, venham todos ajudar, a pescar no mar afora, Bom Jesus dos Navegantes!”. Dessa maneira, a comunidade se apresenta, buscando resistir aos efeitos produzidos pelos grandes empreendimentos e produzindo saúde mental em espaços itinerantes de convivência.

A cultura desses povos do mar, com Bom Jesus dos Navegantes, Iemanjá e outros símbolos da religiosidade e da sua ligação com o território das águas, resiste como expressão de direito à vida e contra as forças do capital. Não obstante, nem sempre a cultura ocupa lugar de resistência. Há momentos nos quais a cultura é consumida e usada pelos próprios empreendimentos da UEO, como na produção de vídeos sobre expressões artísticas da comunidade, mostra e exposição de artesanato da comunidade no shopping center, gerando apenas uma cultura de consumo, como também no ensaio de criação de um museu da pesca, além da exposição de material arqueológico, encontrado durante as escavações para instalação do parque eólico. Essa exposição foi feita na Casa Simplício Dias, já antecipando o esquecimento da memória das águas.

No fundo [dessa produção de subjetividades],
só há uma cultura: a capitalística. É uma cultura
sempre etnocêntrica e intelectocêntrica (ou
logocêntrica), pois separa os universos semi-
óticos das produções subjetivas ${ }^{29(31)}$.

Encontramos convergência entre os estudos e os resultados de outras pesquisas 
realizadas ${ }^{\mathbf{1 0}, \mathbf{2 3}, \mathbf{3 3}, \mathbf{3 4}}$. Os problemas apontados pelas comunidades são comuns, inclusive no que se referem a danos à saúde; diferem no número da população atingida e se a devastação e a destruição afetam fauna e flora com dunas móveis ou fixas com vegetação, além da diferença relativa às singularidades dos territórios em cada área habitada.

Neste estudo, estamos falando da luta pela vida, da determinação social da saúde e da resistência diante da morte à vida comum no território das águas com ecossistemas sensíveis do único Delta das Américas e o terceiro maior do mundo, uma APA, na qual se encontra também uma Reserva Extrativista (Resex). O Delta do Parnaíba é formado por um arquipélago com $2.700 \mathrm{~km}^{2}$ de área, composto por 72 ilhas, abrangendo, portanto, Piauí, Maranhão e Ceará, configurando uma cartografia socioambiental com um rico lençol freático e uma imensa biodiversidade com ecossistemas sensíveis.

Em Xavier/Camocim-CE, povoado com 20 famílias e 66 habitantes que vivem da pesca artesanal, do extrativismo e da agricultura familiar, Mendes relata que "a impermeabilização e compactação de solos para a construção de estradas de acesso, canteiros de obras e áreas para o armazenamento de materiais" ${ }^{33(161)}$ afetou a comunidade de tal forma que a estrada foi a única coisa considerada pela população como positiva. À diferença de Xavier, na Pedra do Sal, nem a estrada, externalidade da instalação da UEO, é considerada boa para o bem viver. A sujeição social imposta ao modo de vida da comunidade gera impactos socioambientais e afeta a saúde: após a construção da estrada de piçarra, que no inverno vira lama e no verão sobra poeira, surgiram problemas que foram denunciados, nas audiências públicas e nas reuniões coletivas propostas e realizadas pelo empreendedor, com a participação da comunidade e representantes das instituições que apoiam a comunidade.

Na reunião coletiva, realizada na Pedra do Sal, a professora Maria (40 anos) inicia se perguntando quais são as áreas de reflorestamento já feitas pela UEO para compensar os impactos ambientais negativos dos empreendimentos D1 e D2. Ela contesta:

O que a gente vê é que nada foi feito. Então, como se dá essa comunicação com vocês? Porque vocês passam em seus carros com vidros fechados. Experimentem passar com os vidros abertos, com poeira e lama afetando, inclusive as crianças da creche, que começaram a ter doenças respiratórias.

Seu Raimundo Boreta (62 anos) problematiza: "a estrada foi feita para que vocês da Ômega tenham acesso, não foi por fazer melhoria para a comunidade".

Durante a leitura das questões encaminhadas à mesa, na audiência pública da Pedra do Sal, a secretária do meio ambiente, ao ler questionamentos encaminhados pela plenária, anuncia: "vocês pensam que me enganam? vocês pensam que uma professora não reconhece a mesma letra?". O racismo que emerge desses enunciados é imediatamente analisado por boa parte da plenária que grita quase em uníssono: "Professora!". Celiane (23 anos), do MPP, contesta: "[...] Como éque você se diz professora de ética ambiental e não sabe que aqui, na comunidade, tem pescador que não sabe ler e escrever?". Na audiência realizada no dia anterior, o secretário de turismo defende a ampliação do parque eólico:

\section{A llha Grande está colaborando com a geração de energia limpa e com a criação de 600 empregos temporários. A Ilha Grande se sente orgulhosa disso. Mas acusam a empresa de causar angústias e anseios na comunidade. [...]. Há pequenos cria- dores que têm o trabalho de uma vida com poucas cabeças de gado e que serão impactados, mas após conversa com a empresa, ela se comprometeu de não afetar tanto.}

A análise desses processos de subjetivação expressa um paradoxo de sujeição e servidão, dada a função social desses representantes do poder público estadual, do 'representante da comunidade' e do poder público municipal; 
essa sujeição social coexiste com a expressão de um desejo servil ao capital.

A gestão social da UEO trata de agenciar moradoras e moradores da comunidade, presidentes de associações comunitárias, gestores e secretários dos municípios para que se somem à campanha de instalação do D10, realizando mais de 50 visitas domiciliares para falar do projeto de ampliação do parque eólico, dos programas sociais e de mitigação dos impactos ambientais. Esse agenciamento chega a produzir mal-estar na comunidade. Irineudo (54 anos), atual presidente da Associação Comunitária da Pedra do Sal, durante uma das três reuniões prévias às audiências públicas que cartografamos, compartilha:

[...] eles [da eólica] estão colocando as pessoas da comunidade umas contra as outras, indo de casa em casa. Me visitando toda hora. Isso é triste!

A comunidade se vê lançada na experiência de um estado concomitantemente estranho e familiar, o que desestabiliza seu contorno e as imagens que ela tem de si mesma e do mundo, provocando-lhe um mal-estar1(56).

Na audiência pública, Andreia, psicóloga e representante do Conselho Municipal de Saúde de Ilha Grande, fez a seguinte problematização: "estudos em relação aos morcegos mostram que, em suma, a morte dos mesmos tem sido por hemorragia e não por impacto nas turbinas [dos aerogeradores]". Preocupada, ela acrescenta, "nós também somos mamíferos". E relata:

Emissão de ruídos em decibéis do tipo $B$ e $C$ que são chamados de infrassom são sentidos como vibração no corpo e podem causar: distúrbios do sono; dor de cabeça; zumbido nos ouvidos; pressão no ouvido; náuseas; tonturas; taquicardia; irritabilidade; problemas de concentração e memória; episódios de pânico com sensação de pulsação interna ou trêmula quando se acorda ou dorme.

Há uma contradição entre o cuidado que emerge como dispositivo dos processos de subjetivação que marcam os enunciados da conselheira municipal de saúde e as instituições do Estado que dão aval ao empreendimento da UEO. Para a maioria das pessoas da comunidade que compareceram às audiências, a UEO não produz vida no território, seus programas sociais servem apenas para denunciar a ausência das políticas públicas e a incompetência dos governos e para confundir a população local. Além da energia que produz não servir para a comunidade, por se tratar de uma empresa produtora, e não de distribuidora, nesses cinco anos de ocupação do território pela UEO, os programas de monitoramento das áreas do D1 e do D2 operam na lógica de vigiar e reprimir, ferindo o direito de ir e vir da comunidade, afetando a determinação social da saúde no que se refere ao acesso ao território das águas e à segurança alimentar.

Em relação à vigilância e ao controle dos corpos, na restrição à liberdade de ir e vir da comunidade, prevalece sujeição e segmentariedade dos modos de subjetivação. Seu Zé Boreta, que na reunião coletiva havia questionado:

Será que esses aerogeradores construídos com cimento e outros produtos, soltando óleos; será que não poluem a água? Vocês que têm estudo e são estudados, digam.

Na audiência pública, ele responde, fazendo a tradução para quem ainda não entendeu o que está acontecendo:

[...] Vão implantar mais 52 aerogeradores. Émais maldade para nós. É mais poluição de óleo nas lagoas. É mais ruindade para cada um de nós. Nós estamos nos encontrando numa engrenagem acurralados, sem ver saída. Estão nos cercando, estão nos cercando por todos os lados. Estão cerceando nosso direito de ir e vir. Antes, nós tínhamos o direito. Hoje, não temos mais porque tem um vigilante que diz: 'aqui, você não pode passar'. Por que se a gente vive aqui? Por que tiraram nosso direito? Vocês não sabem disso porque vocês nunca conviveram com essa realidade. Eu estou falando é 
de nós pescadores. Nós que reside na comunidade. Eu estou falando é de nós pescadores não é de quem tem seu bom salário, que eu não sou contra. [...]. Mas vocês não podem dizer que não estão acabando com a Ilha que não estão acabando com o meio ambiente. Eu estou dizendo, porque eu conheço. Vai ter mais poluição. Vai ter mais destruição. E mais desafio para nós.

Trata-se do desafio de enfrentar o racismo ambiental. Trata-se do desafio de lutar para desativar o disposto do estado de exceção e de enfrentar um conjunto de políticas de morte ao território das águas, morte à dimensão política da vida nesse território por meio dos agenciamentos dos modos de vida para a cultura e produção do desejo de consumo ${ }^{29}$. Nesse sentido, a mortificação do território existencial é uma maquinação para a apropriação desordenada e desenfreada das terras, das águas e dos ventos, feito e efeito das relações de poder cujas ações sociais, jurídicas, econômicas e políticas corroboram o lucro exorbitante dos empreendimentos eólicos em nome do desenvolvimento econômico sustentável, mesmo que tal empreendimento afete a determinação social da saúde da comunidade de pesca artesanal, no que se refere à segurança alimentar, ao acesso à renda e ao próprio território.

\section{Cartografia das cartografias: considerações finais}

A produção de subjetividade colonial-capitalística $^{1}$ trata de manter uma política de morte ao território das águas - na APA Delta - e a outras comunidades tradicionais do Brasil. $\mathrm{O}$ estado de exceção tem políticas de vida para quem merece viver com os benefícios do capitalismo contemporâneo e políticas de morte às formas de vida de quem vive nos territórios tradicionalmente ocupados. No território das águas, os empreendimentos econômicos de grande porte geram conflitos e frustação na comunidade, haja vista que as atividades hegemônicas envolvem empresas de alto poder aquisitivo e ocorrem se sobrepondo até as decisões em contrário em audiências públicas, nos fóruns e em reuniões sobre regulamentação de atividades econômicas na APA.

Como vimos anteriormente, a política de morte ao território existencial se inicia com a produção de conflitos e vulnerabilidade social, afetando a segurança alimentar e a produção da economia de base familiar, o acesso ao território e ao trabalho artesanal, fontes da geração de renda da comunidade extrativista. Esses dispositivos emergiram da análise dos processos de subjetivação cuja problematização nos fez ver e nos faz pensar como a determinação social da saúde é afetada, abalando e comprometendo as bases dos processos psicossociais de promoção da saúde ${ }^{35}$.

Dada a complexidade desses processos de subjetivação que se configuram na luta pela dimensão política da vida e na resistência contra a soberania do capital que se impõe na APA Delta Parnaíba, reconhecemos que há articulação de dispositivos econômicos, jurídicos, educacionais, políticos, sociais e ambientais para implementação dos empreendimentos eólicos no território das águas. Essa articulação faz parte dos agenciamentos capitalísticos que captam recursos socioambientais de ecossistemas sensíveis e que tratam de cooptar as comunidades constituídas de pescadoras e pescadores artesanais, extrativistas, artesãs e pequenos comerciantes, tais como donos de pequenas pousadas, bares e pequenos restaurantes.

Um dos dispositivos desses agenciamentos é o racismo ambiental que é acionado pela soberania do capital para compor o estado de exceção, com os governos federal, estadual e municipal, políticos e lideranças de algumas instituições.

Há problemas de saúde relacionados com os determinantes ambientais que se agravam em períodos de chuva, em razão de não haver coleta de lixo em todas as localidades; além de não haver saneamento básico, muitas vezes, 
falta água potável; o acesso aos serviços de saúde é dificultado por falta de cobertura de ACS e de transporte público. Como se não bastassem esses problemas de saúde ambiental e sanitária, a precarização da vida se amplia com a imposição da soberania do capital, afetando a determinação social da saúde e a dimensão política da vida de tal modo que o desequilíbrio provocado pela geração da chamada 'energia limpa' afeta as ecologias ambiental, subjetiva e social no que se refere à segurança alimentar, ao acesso à pesca artesanal, à renda, ao território das águas e à saúde ambiental no território.

Nesse campo de disputas, a luta em defesa da saúde ambiental sanitária e a resistência à soberania do capital como formas de sustentação de um modo de vida se configuram como produtoras de saúde. Do mesmo modo, saúde comunitária ganha força como potência de vida e agenciamento coletivo do desejo das pescadoras e dos pescadores artesanais, como demostramos por meio da análise dos processos de subjetivação que se conformam nos relatos e escrita de $\mathbf{s i}^{\mathbf{1 9 , 2 0}}$ apresentados. A precarização da vida e da determinação social da saúde, portanto, não os impede de viver em "uma zona de vida comunitária"22(13) e de que possam levar uma forma de vida na comunidade tradicional de pesca artesanal, na qual "está em jogo o próprio viver, e no seu viver, está em jogo antes de tudo o seu modo de viver"27(13-14) e produzir saúde.

\section{Colaboradores}

Félix-Silva AV (0000-0003-3084-379X)*, Oliveira MMS (0000-0001-6818-8319)*, Bezerra LLS (0000-0003-0650-0498)* contribuíram igualmente para a elaboração do manuscrito.

\section{Referências}

1. Rolnik S. Esferas da Insurreição. São Paulo: n-1 edições; 2018.

2. Pelbart PP. Estamos em guerra. São Paulo: n-1 edições; 2017.

3. Schwarcz LM, Starling HM. Brasil: Uma biografia. São Paulo: Companhia das Letras; 2015.
4. Castro EV. Os Involuntários da Pátria. São Paulo: n-1 edições; 2016.

5. Castro EV. Brasil, o País do Futuro do Pretérito. São Paulo: n-1 edições; 2019.

6. Nascimento A. O Genocídio do negro brasileiro: Processo de um Racismo Mascarado. São Paulo: Perspectiva; 2016.
${ }^{*}$ Orcid (Open Researcher and Contributor ID). 
7. Jesus V. Racializando o olhar (sociológico) sobre a saúde ambiental em saneamento da população negra: um contínuo colonial chamado racismo ambiental. Saúde soc. [internet]. 2020 [acesso em 2020 maio 25]; 29(2):e180519. Disponível em: https://doi.org/10.1590/ s0104-12902020180519.

8. Agamben G. O uso dos corpos. São Paulo: Boitempo; 2017. Série [Estado de sítio, Homo Sacer, IV, 2].

9. Santos BS. Direitos humanos, Democracia e Desenvolvimento. In: Santos BS, Chauí M. Direitos humanos, Democracia e Desenvolvimento. São Paulo: Cortez; 2013. p. 41-133.

10. Brannstrom AGC. Diretrizes para o Planejamento Socialmente justo com vistas à Implantação de Parques Eólicos no Brasil. In: Gorayeb A, Brannstrom C, Meireles AJ, organizadores. Impactos socioambientais da implantação dos parques de energia eólica no Brasil. Fortaleza: Edições UFC; 2019. p. 25-44.

11. Estudo de Impacto Ambiental. OMEGA Energia Complexo Eólico Delta 10. Piauí: Mineral Engenharia e Meio Ambiente; 2018.

12. Brasil. Decreto de 28 de agosto de 1996. Casa Civil. Dispõe sobre a criação da Área de Proteção Ambiental Delta do Parnaíba, nos Estados do Piauí, Maranhão, e Ceará, e dá outras providências, 1996 [internet]. [acesso em 2019 maio 20]. Disponível em: http:// www.planalto.gov.br/ccivil_03/DNN/Anterior\%20 a\%202000/1996/Dnn4368.htm.

13. Cadastro Brasileiro de Ocupações. Pescador Polivalente [internet]. 2017 [acesso em 2019 maio 20]. Disponível em: http://www.mtecbo.gov.br/cbosite/pages/home.jsf.

14. Instituto Brasileiro de Geografia e Estatística. Censo Demográfico - 2010 [internet]. 2011 [acesso em 2019 maio 20]. Disponível em https://censo2010.ibge.gov. br/.

15. Parnaíba. Prefeitura. Mapa da Unidade Básica de Saúde da Pedra do Sal. Parnaíba: UBS Pedra do Sal, 2018.
16. Brasil. Ministério da Saúde. Política Nacional de Saúde Integral das Populações do Campo e da Floresta. Brasília, DF: Ministério da Saúde; 2013.

17. Guattari F. As três Ecologias. 13. ed. Campinas: Papirus; 2002.

18. Barros LP, Kastrup V. Cartografar é acompanhar processos. In: Passos E, Kastrup V, Escóssia L, organizadores. Pistas do método da cartografia: pesquisa-intervenção e produção de subjetividade. Porto Alegre: Sulina; 2009. p. 52-75.

19. Rago LM. A aventura de contar-se: feminismos, escrita de si e invenções da subjetividade. São Paulo: UNICAMP; 2013.

20. Butler J. Relatar a si mesmo. Belo Horizonte: Autêntica; 2015.

21. Rocha FMR, Braga OR, Melo SP. A Sereia Mariá e as Histórias das Comunidades da APA Delta do Parnaíba. Parnaíba: Sieart; 2015.

22. Agamben G. Uma biopolítica menor. São Paulo: n-1 edições; 2016.

23. Figueiredo EBG. É doce morrer no mar? Análise psicossocial do ingenium da pesca artesanal. [tese]. São Paulo: Pontifícia Universidade Católica; 2018. 175 p.

24. Hui Y. Da consciência infeliz dos neorreacionários. São Paulo: n-1 edições; 2019.

25. Lazzarato M. É o capitalismo, estupido! [internet]. 2020 [acesso em 2020 maio 25]. Disponível em: https://n-ledicoes.org/016.

26. Mbembe A. Necropolítica: biopoder, soberania, estado de exceção, política de morte. 2. ed. São Paulo: n-1 edições; 2018.

27. Agamben G. Meios sem fim: notas sobre a política. Belo Horizonte: Autêntica; 2017.

28. Ribeiro D. Lugar de Fala. São Paulo: Letramento; 2019. 
29. Guattari F, Rolnik S. Micropolítica: Cartografia do desejo. 10. ed. Petrópolis: Vozes; 2010.

30. Guattari F. Revolução Molecular: pulsações políticas do desejo. 3. ed. São Paulo: Brasiliense; 1981.

31. Negri T, Guattari F. As verdades Nômades: por novos espaços de liberdade. São Paulo: Autonomia Literária; 2017.

32. Mbembe A. Necropolítica. São Paulo: n-1 edições; 2018.

33. Gondim LB, Oliveira CD, Xavier TF. Os ventos da Ibiapaba: Percepções sobre o litígio territorial Ceará - Piauí no impacto dos parques eólicos. In: Gorayeb A, Brannstrom C, Meireles AJ, organizadores. Impactos socioambientais da implantação dos par- ques de energia eólica no Brasil. Fortaleza: Edições UFC; 2019. p. 213-228.

34. Mendes JS. Contradições do discurso sustentável da energia "limpa": Problemas locais versus soluções regionais. In: Gorayeb A, Brannstrom C, Meireles AJ, organizadores. Impactos socioambientais da implantação dos parques de energia eólica no Brasil. Fortaleza: Edições UFC; 2019. p. 159-178.

35. Brasil. Ministério da Saúde. Política Nacional de Promoção da Saúde. 3. ed. Brasília, DF: Ministério da Saúde; 2010.

Recebido em 30/09/2019

Aprovado em 03/07/2020

Conflito de interesses: inexistente

Suporte financeiro: não houve 